\title{
SPRAY DEPOSITION WITHIN PLANT CANOPIES
}

\author{
B. RICHARDSON ${ }^{1}$ and M. NEWTON ${ }^{2}$ \\ ${ }^{1}$ Forest Research, Private Bag 3020, Rotorua, New Zealand \\ ${ }^{2}$ Dept. Forest Science, Oregon State University, Corvallis, OR, 97331, USA
}

\begin{abstract}
Spray deposition was measured within canopies of bracken fern (Pteridium aquilinum) and greenleaf manzanita(Arctostaphylos patula) following ground application of a spray mixture containing water, a fluorescent tracer and surfactant. A high proportion of spray (35-38\%) reached the ground through manzanita canopies whereas only $1-13 \%$ reached the ground through a bracken canopy. Spray deposition was closely linked to the quantity of foliage projected on a plane normal to the trajectory of droplets passing through the canopy. Droplets that had trajectories with a significant horizontal velocity component were more effectively captured because of an increase in the quantity of foliage in their path.
\end{abstract}

Keywords: spray deposit, deposition, drift, herbicide, canopy penetration.

\section{INTRODUCTION}

To minimise the production of small, drift prone droplets (diameters $<100-150$ $\mu \mathrm{m})$, herbicides are often applied using techniques that produce sprays with volume median diameters (VMDs) in excess of $800 \mu \mathrm{m}$ (Richardson et al. 1996; Spillman 1982). Use of foliar applied sprays comprised of large droplets can have implications in terms of herbicide efficacy and canopy penetration (Knoche 1994), and consequent ground contamination. The distribution of spray deposits within canopies depends on (1) impaction efficiency, (2) leaf surface retention and (3) the amount of foliage in the path of droplets. Impaction efficiency will be high with large droplets (Spillman 1984), but overall retention may decrease. However, this also depends on other factors such as foliage angle, surface characteristics of the foliage, physical properties of the liquid, total spray volume and droplet velocity (Lake 1977; Hartley and GrahamBryce 1980).

Movement of large droplets in low wind speeds, is dominated by gravity, as opposed to aerodynamic forces (Spillman 1982), and droplets "sediment" onto leaf surfaces. The probability of sedimenting droplets impacting on foliage should be related to the vertically projected plan area of the plant or gap fraction (Richardson and Newton, in press). Therefore, canopies with leaves oriented horizontally are more likely to effectively capture large droplets than canopies with vertical foliage (Bache 1985; Spillman 1984). Existing spray application models such as SpraySafe Manager (Ray et al. 1999) already model droplet trajectories. Models of spray interception by canopies that account for foliage structure also exist (Bache 1985) but their validation has been limited.

The purpose of this study was to measure the distribution of spray deposits in canopies of bracken fern (Pteridium aquilinum L. Kuhn) and greenleaf manzanita (Arctostaphylos patula Greene) in relation to droplet size, droplet trajectory, spray application volume and canopy structure. As well as providing useful information on the proportion of spray reaching the intended target, this will provide data that subsequently can be used to improve models of spray interception by plant canopies. Bracken fern and manzanita were selected for this study because they are important forest weed species in the Pacific North West of the USA. 


\begin{abstract}
METHODS
Sites

Four manzanita and five bracken plots $(10 \times 3 \mathrm{~m})$ were selected to provide uniform, continuous canopies. Detailed measurements were made of canopy structure within the central portion of each plot using two-dimensional point quadrats (Warren Wilson 1959; Richardson and Newton in press). Manzanita is an evergreen shrub, with small (approximately $20-30 \mathrm{~mm}$ long), oval-shaped leaves oriented at about $72^{\circ}$ from horizontal. Manzanita plots were up to $1.4 \mathrm{~m}$ tall and had leaf area indices (LAIs) between 2 and 3 (Richardson and Newton, in press). Bracken fern was up to $1.3 \mathrm{~m}$ tall with LAIs of approximately 2.5 to 3.5 .
\end{abstract}

\title{
Spray application and measurement
}

A spray mixture of water plus surfactant (0.5\% Mon 0817 Monsanto Co.) and 300 ppm Rhodamine B dye was applied using hand-held sprayers. Four treatments (replicated five times), comprising two droplet sizes (VMDs of 290 and $810 \mu \mathrm{m}$ ) at two spray volumes (50 and 100 litres/ha), were applied with spinning discs to all plots of each species. A further treatment using the fan nozzle was applied to three plots of each species, comprising droplets with a VMD of $195 \mu \mathrm{m}$ and spray volume of 100 litres/ha. All applications were made under conditions of low wind (less than $1 \mathrm{~m} / \mathrm{s}$ ), with temperature less than $20^{\circ} \mathrm{C}$ and relative humidity greater than $45 \%$.

Spray was sampled on horizontal strings threaded through the width $(3 \mathrm{~m})$ of the canopies at 4 to 6 heights, depending on canopy height. Deposits were quantified by fluorimetry of recovered Rhodamine B. The top string was positioned above the canopy, to provide a measure of actual application rate. Strings were kept in the dark until analysis with a fluorimeter (Model 112, Sequoia-Turner) (generally within 48 hours of application) to prevent photo-decomposition of Rhodamine B. Only deposits on the central $1 \mathrm{~m}$ of each string were measured to minimise edge effects. Each treatment was applied and replicated with fresh strings in the same location. This technique allowed comparison of treatments while canopy structure, normally a difficult to control variable, was held constant.

Most treatments were applied using three spinning discs (Herbi, Micron Sprayers Ltd) mounted on a $3 \mathrm{~m}$ hand-held boom and with the boom 0.7-1.0 $\mathrm{m}$ above the canopy. Droplets from these applications were observed to enter the canopies with trajectories tending to vertical.

To examine the effect of a rapidly changing trajectory on deposition profiles, applications to three plots of each species were also made with a hand-held boom sprayer, fitted with 80015 flat fan nozzles (Spraying Systems Co.) and pressurised to $207 \mathrm{kPa}$. The boom was held with the nozzle tips $0.25-0.30 \mathrm{~m}$ above the canopy and angled back at approximately $30^{\circ}$ from the horizontal. Thus, droplets entered the canopy with a high horizontal velocity component compared to the spinning disc applications.

\section{Analysis}

All deposition data were expressed as a percentage of the nominal application rates. The coefficient of variation $(\mathrm{CV})$ of spray deposition was assessed using the central $1 \mathrm{~m}$ of each string located above the canopy.

Deposition within each layer of the canopy was calculated as the difference in deposition on consecutive strings. It was assumed that the rate of spray attenuation would be related to the amount of foliage projected onto a plane perpendicular to the droplet trajectory (Bache 1985; Bache and Uk 1975). Deposit data were fitted to an exponential decay model of the form:

$$
\mathrm{D}=\mathrm{a} \mathrm{e}^{-\mathrm{b}\left(\mathrm{F}_{\theta}\right)}
$$

where $\mathrm{D}$ is the quantity of spray (percent of application rate) deposited per unit length of string at any canopy level, a is the intercept (the initial quantity of spray), $\mathrm{b}$ is the attenuation coefficient and $\mathrm{F}_{\theta}$ is the quantity of foliage $\left(\mathrm{m}^{2}\right.$ foliage $/ \mathrm{m}^{2}$ ground presented in a plane normal to the droplet trajectory, $\theta$, and summed from the top of the canopy down. Since the trajectories of droplets from the spinning disc application tended to vertical, $\theta$ was equal to $90^{\circ}$. $\mathrm{F}_{\theta}$ includes leaves, twigs and stems, and should 
not be confused with leaf area index (LAI). LAI is the total amount of one-sided leaf area (i.e. independent of leaf orientation) per unit ground area and is independent of droplet trajectory. $\mathrm{F}_{\theta}$ will normally vary with droplet trajectory angle and leaf inclination angle. The suitability of this model was examined by inspecting residual plots and by calculating the Kolomogorov-Smirnov statistic for testing the normality of error terms. Indicator (dummy) variables were used to test for differences between treatments in slopes of deposition profiles.

\section{RESULTS AND DISCUSSION}

String, in conjunction with fluorescent tracers, has been used as a spray collector in a number of deposition and drift studies (Sanderson et al. 1991) using methods described by Whitney and Roth (1985). String has the advantage that it collects spray with equal efficiency independent of droplet trajectory. It has been shown previously that fluorescence on string is linearly correlated with the application rate (correlation coefficients > 0.997) (Whitney and Roth 1985).

\section{Application variability}

No significant differences were found among the CVs for deposition from any treatment $(\mathrm{P}>0.90)$, thus, all treatments were applied with equal precision. Mean coefficients of variation for spinning disc and fan nozzle applications were 16 and $14 \%$, respectively, but there was a wide range from approximately 5 to $35 \%$.

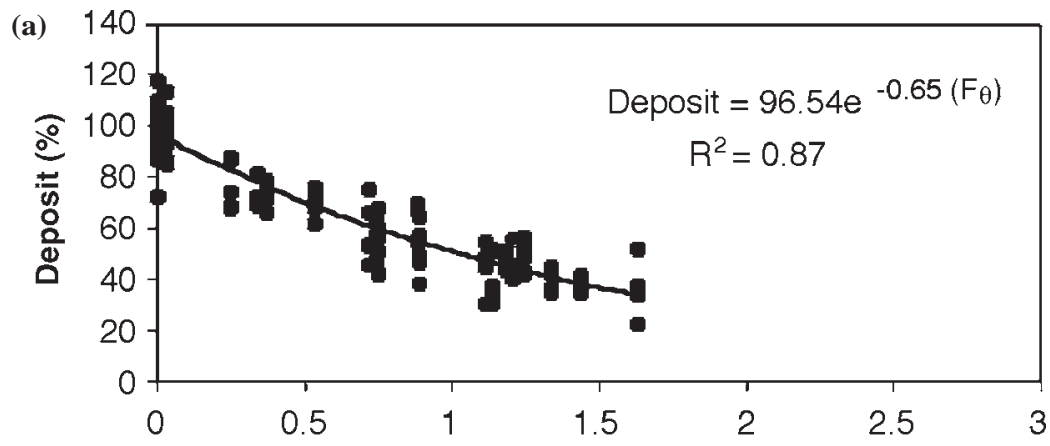

Foliage area, $F_{\theta}\left(\mathrm{m}^{2} / \mathrm{m}^{2}\right)$

(b)

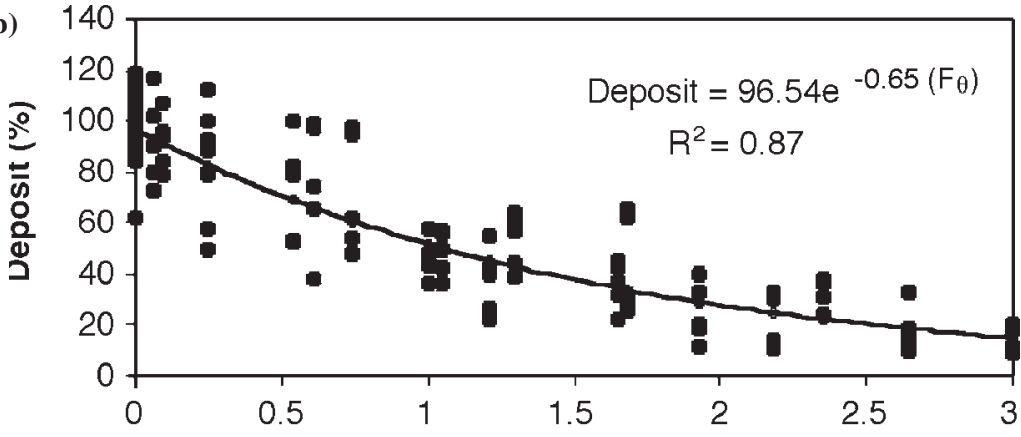

Foliage area, $F_{A}\left(\mathrm{~m}^{2} / \mathrm{m}^{2}\right)$

Figure 1: Relationship between spray deposit, from applications using large droplets at 100 litres/ha, and foliage area in vertical projection summed from the top of the canopy down for (a) manzanita and (b) bracken canopies. The fitted regression model is also indicated. 


\section{Deposition profiles}

The proposed model proved satisfactory for describing deposition profiles from all of the spinning disc treatments (Table 1; Fig. 1). Between 73 and $87 \%$ of the variation in deposition could be explained by $\mathrm{F}_{\theta}$. The slopes of the lines describing deposit attenuation per unit of vertically projected foliage area (parameter b) are similar for both species. This supports the hypothesis that deposition profiles are strongly linked to the quantity of foliage projected perpendicular to the droplet trajectory. Deposit attenuation per unit of height is much greater with bracken, probably because this species has a shorter, more compact canopy and a more horizontal foliage inclination than manzanita.

Although spray deposition profiles followed a pattern of exponential decay with respect to $F_{\theta}$, canopy height will not necessarily be a good predictor of deposition. The relationship between $\mathrm{F}_{\theta}$ and height depends on the distribution of leaf area and leaf angle, and droplet trajectory.
TABLE 1: Regression models for spray deposit profiles in bracken and manzanita canopies from treatments applied using spinning disc and fan nozzles.

$\begin{array}{llll}\text { Treatment }^{1} & \mathrm{Model}^{2} & \text { SE of estimate }\end{array}$

Herbi:

$\begin{array}{llll}\text { L50 manzanita } & \mathrm{D}=97.5 \mathrm{e}^{-0.65\left(\mathrm{~F}_{\theta}\right)} & 0.79 & 0.19 \\ \text { L100 manzanita } & \mathrm{D}=96.5 \mathrm{e}^{-0.65\left(\mathrm{~F}_{\theta}\right)} & 0.87 & 0.14 \\ \text { S50 manzanita } & \mathrm{D}=96.5 \mathrm{e}^{-0.68\left(\mathrm{~F}_{\theta}\right)} & 0.84 & 0.17 \\ \text { S100 manzanita } & \mathrm{D}=96.5 \mathrm{e}^{-0.71\left(\mathrm{~F}_{\theta}\right)} & 0.86 & 0.15 \\ \text { L50 bracken } & \mathrm{D}=90.9 \mathrm{e}^{-0.71\left(\mathrm{~F}_{\theta}\right)} & 0.80 & 0.34 \\ \text { L100 bracken } & \mathrm{D}=96.5 \mathrm{e}^{-0.63\left(\mathrm{~F}_{\theta}\right)} & 0.78 & 0.31 \\ \text { S50 bracken } & \mathrm{D}=93.7 \mathrm{e}^{-0.72\left(\mathrm{~F}_{\theta}\right)} & 0.82 & 0.32 \\ \text { S100 bracken } & \mathrm{D}=94.6 \mathrm{e}^{-0.65\left(\mathrm{~F}_{\theta}\right)} & 0.83 & 0.28 \\ \text { Fan: } & & & \\ \text { 30 manzanita } & \mathrm{D}=93.7 \mathrm{e}^{-0.91\left(\mathrm{~F}_{\theta}\right)} & 0.65 & 0.27 \\ \text { 30 bracken } & \mathrm{D}=96.5 \mathrm{e}^{-0.86\left(\mathrm{~F}_{\theta}\right)} & 0.68 & 0.34\end{array}$

${ }^{1}$ For spinning disc treatments, $\mathrm{L}$ and $\mathrm{S}$ represent large and small droplets respectively, and 50 or 100 is the application rate in 1itres/ha.

${ }^{2}$ Spray deposit, D, was related to the cumulative foliage area in vertical projection, summed from the top of the canopy down, $\left(\mathrm{F}_{\theta}\right)$.

Although the linear association was statistically significant for fan nozzle treatments (Table 1), the residuals showed a distinct lack of fit. This probably resulted from use of an incorrect independent variable. If cumulative foliage area in a vertical projection (i.e. $\theta=90$ ) is to be the appropriate independent variable, droplets should be falling along more-or-less vertical trajectories. The quantity of foliage 'apparent' to droplets moving along trajectories other than vertical varies considerably (Richardson and Newton, in press) and consequently their likelihood of deposition also varies. Due to their high initial horizontal component, droplets produced by the fan nozzle applications would have followed rapidly changing trajectories and the actual foliage area in the path of the droplets is not well represented by $F_{\theta}$, where $\theta=90$. Other studies have shown that trajectory modification to increase the "apparent" foliage area also significantly increases deposition (Gohlich 1985; Taylor et al. 1989).

The total amount of spray passing through the canopy to the ground is much greater with manzanita because of the relatively low quantity of foliage presented in vertical projection (leaves tending to vertical). Using the mean foliage area values for the experimental plots, the quantity of vertically falling spray predicted to reach the ground ranged from $9.7-12.7 \%$ for bracken and 34.7-37.9\% for manzanita, depending on the treatment. Although the regression models for fan nozzle applications were 
unsatisfactory, they give an indication of how attenuation would vary if spray was given a significant horizontal component. Ground deposition for the fan is likely to be about 8.4 and $25.2 \%$ for bracken and manzanita, respectively. This represents a substantial reduction in ground deposition for manzanita and a small reduction with bracken compared to the spinning disc treatments, and probably relates to their respective foliage orientation.

Treatments applied to manzanita plots did not produce significant differences in deposit attenuation $(\mathrm{P}>0.05)$. With bracken, droplet size had no significant effect on deposit attenuation, but attenuation was significantly greater with 50 litres/ha applications than at 100 litres/ha $(\mathrm{P}=0.016)$. This effect was particularly noticeable with large droplets $(\mathrm{P}=0.07)$, giving some indication of a droplet size-volume interaction. The reason for this is unclear but previous studies have shown that spray recovery on bracken species increases as volume of application decreases (Richardson et al. 1986). It is unlikely that runoff would cause large differences at these low application volumes but droplet reflection from previously wetted surfaces (Richardson et al. 1986; Spillman 1984) may have been a factor.

\section{REFERENCES}

Bache, D.H., 1985. Prediction and analysis of spray penetration into plant canopies. Pp 183-190 In: British Crop Protection Council Monograph No. 28: Application and Biology, E.S.E. Southcombe (Ed); BCPC Publications, Croydon, England.

Bache, D.H. and S. Uk., 1975. Transport of aerial spray, II. Transport within a crop canopy. Agric. Meteorol. 15: 371-377.

Gohlich, H., 1985. Deposition and penetration of sprays. Pp 173-183In: British Crop Protection Council Monograph No. 28: Application and Biology, E.S.E. Southcombe (Ed); BCPC Publications, Croydon, England.

Hartley, GS. and Graham-Bryce, I.J., 1980. Physical Principles of Pesticide Behaviour. Academic Press, London.

Knoche, M., 1994. Effect of droplet size and carrier volume on performance of foliage-applied herbicides. Crop Prot. 13: 163-178.

Lake, J.R., 1977. The effect of drop size and velocity on the performance of agricultural sprays. Pestic. Sci. 8: 515-520

Ray, J.W., Richardson, B., Schou, W.C., Teske, M.E., Vanner, A.L. and Coker, G.W.R., 1999. Validation of SpraySafe Manager, an aerial application decision support system. Can. J. For. Res. 29: 875-882.

Richardson, B. and Newton, M. Analysis of plant canopy structure to predict herbicide deposit distribution. N.Z. J. For. Sci.: (in press).

Richardson, B., Ray, J. and Vanner, A., 1986. Retention of spray on bracken pinnae: effect of application volume and formulation. N.Z. J. For. Sci 16: 87-95.

Richardson, B., Ray, J., Vanner, A., Davenhill, N. and Miller, K., 1996. Nozzles for minimising herbicide spray drift. N.Z. J. For. Sci 26: 438-448.

Sanderson, R., Huddleston, E.W., Ross, J.B., Hewitt, A.J. and Bartee, S.N., 1991. Comparison of the drift potential and droplet size spectra produced by different formulations of propanil and adjuvants. ASAE Paper No. AA91-008. ASAE St. Joseph, MI 49085-9659, USA.

Spillman, J.J., 1982. Atomizers for the aerial application of herbicides - ideal and available. Crop Prot. 1: 473-482.

Spillman, J.J., 1984. Spray impaction, retention and adhesion: an introduction to basic characteristics. Pestic. Sci. 15: 97-106.

Taylor, W.A., Andersen, P.G. and Cooper, S., 1989. The use of air assistance in a field crop sprayer to reduce drift and modify drop trajectories. Proc. Brighton Crop Prot. Conf. - Weeds: 631-639

Warren Wilson, J. 1959. Analysis of the spatial distribution of foliage by twodimensional point quadrats. New Phytol. 58: 92-101.

Whitney, R.W. and Roth, L.O. 1985. String collectors for spray pattern analysis. ASAE Paper No. 85-1005. ASAE, St. Joseph, MI, 49085, USA. 